\title{
Development and Application of the Bidding Decision Support System for Water Project
}

\author{
Bin Wang and Tiexin Cheng \\ College of Management, Tianjin Polytechnic University, \\ Xiqing, Tianjin, China \\ lucky1115@sohu.com\& tiexincheng@vip.sina.com
}

\author{
Yiwang Wang \\ Tianjin Water Project Construction and Transaction, \\ Service Centre, Hexi, Tianjin, China \\ wangyiwang@sina.com
}

\begin{abstract}
In this paper, according to current research on tender evaluation methods and bidding systems, the tender evaluation model was established and described in detail, and the framework and functions of the new bidding DSS(Decision Support System) of water projects in Tainjin were designed and illustrated, which was based on the principles of fairness, justice and openness. With friendly interface, advanced IT techniques and simple operation, this new system can be applied to the whole process management of water project bidding, which can reduce the cost of bidding management and human fault and improve the efficiency of bidding.
\end{abstract} System)

Keywords-Water project; Bidding; DSS(Decision Support

\section{INTRODUCTION}

Bidding is a method of competitive procurement, which can bring more economical and higher quality projects, goods or services to the purchasers. It is also the internationally used and verified project procurement method, which is adopted widely by developed countries and most of developing countries. Bidding for water projects is a complex system, concerning project owner, contractor, evaluation experts, design engineers, relevant authorities, etc. The activities of bidding need to process amounts of complex data and information, and considering artificial bidding and tender evaluation lack of efficiency with high cost, the application of information technology to bidding for water projects needs to be extended.

With the development of IT, the bidding system based on Web is a kind of trend, which can provide an open and fair information processing platform, further standardize bidding process, and promote the bidding process into informatization.

\section{LITERATURE REVIEW}

In 2000, El-Mashaleh M S[1] described the process design of E-bidding system in detail, and discussed the problems in the process of implementation system, which was based on the bidding decision model. Gokhan Arslan, Mustafa Tuncan, M.Talat Birgonul, Irem Dikmen[2] proposed the functions and procedures of the Web-based bidding system, discussed its development mode, and analyzed the problems and solutions of it when it was put into practice. Park W. R[3] established the electronic business platform for bidding with XML, through which bidders can exchange data more conveniently. KinOnn Wong[4] set up Agent-electricity Market Bidding System, in which the distributive artificial intelligence was applied into design of it in order to promote electronization and intellectualization for bidding.

In 2001, Lu Yaobin, Zhu Zhiwei, Zhang Jinlong[5] proposed main framework and functions of a Web-based bidding system in the paper "The Design and Implementation of Bidding \& Tendering System Based on Web”, gave the development mode, and analyzed the problems in the process of the system. Wang Shenya[6] described the design and implementation of Internet based Bidding System in detail, and discussed system functions for the specific needs of the enterprises. In 2006, He Xiaoqin, Song Wei, Liu Weining[7] set up the tender evaluation model based on AHP(Analytic Hierarchy Process) of group decision, according to which the framework and functions of the tender evaluation system was proposed. Zhang Qingfeng[8] proposed a complete solution of one public Web-based bidding subsystem in the paper "The Design and Realization of the Public Bidding Sub-system Base on Web", which was applied to the project of Sichuan e-bidding system with software engineering idea. Other scholars, such as Lv Zhiguo[9], Sun Yongmei[10], Shi Hairong[10], Deng Ronghui[11], Tian Zhong, Liu Yuming[12], conducted same research in this field or developed similar systems.

The online bidding systems were applied in all over the world widely, nevertheless, most of them played a role on bidding information release and few bidding systems offered all bidding life cycle management online, including call for bid, tender evaluation, bidder award, etc. In addition, few bidding systems were developed for water projects; moreover, water project bidding is a complex system, requiring numerous human resources, expenditure, and efforts. The bidding decision support system of Tianjin water projects illustrated below can make the entire process of bidding electronized and automated, which can greatly improve bidding and procurement efficiency.

\section{The Tender Evaluation Model in The Tianjin WATER PROJECT BIDDING DSS}

In the traditional process of bidding, tender evaluation was the key factor, which directly affected the results of the bidding. Therefore, it is very important to establish scientific tender evaluation decision model in order to indemnify tender evaluation fair and objective with the bidding DSS. 


\section{A. Establishment of the Tender Evaluation Model}

1) Bidders Offer Price Scoring Model

The bidders offer price scoring model in the DSS is set up below:

$$
c_{i}=a-\left[\left(b_{i}-b\right) / b\right] \times 100 \quad\left(b_{i} \geq b, i=1, \ldots, k\right)
$$

Where:

$C_{i}$ : The mark of the offer price of the bidder $i$;

$b_{i}$ : The offer price of the Bidder $i$;

$b$ : The base offer price, which can be obtained as follows:

$$
b=\left[\sum_{i=1}^{k} b_{i}-\max \left(b_{1} \sim b_{k}\right)-\min \left(b_{1} \sim b_{k}\right)\right] \times \omega
$$

Where:

$\omega$ : Coefficient weights of offer price;

$k$ : The number of bidders;

2) Technical proposal Scoring Model

The technical proposal scoring model is set up below:

$$
d_{i}=\frac{\sum_{j=1}^{n} m_{i j}}{n}
$$

Where:

$d_{i}$ : The mark of the technical proposal of the bidder $i$;

$m_{i j}$ : The mark given by the expert $j$ for the bidder $i$

about the technical proposal;

$n$ : The number of experts;

3) Commercial proposal Scoring Model

The commercial proposal scoring model is set up below:

$$
e_{i}=\frac{\sum_{j=1}^{n} p_{i j}}{n}
$$

Where:

$e_{i}$ : The mark of the commercial proposal of the bidder $i$;

$p_{i j}$ : The mark given by the expert $j$ for the bidder $i$ about the commercial proposal;

$n$ : The number of experts;

\section{4) Bidder's Total Scoring Model}

Finally, the bidder's total scoring model is established as follows:

$$
v_{i}=c_{i}+d_{i}+e_{i}
$$

With the model, each bidder's final total mark can be calculated, according to which the bidder list can be ranked, then, the top one of them will be recommended to be accepted as the winner candidate.

\section{THE FrameWORK AND FunCtion ANAYSIS OF BIDDING DSS FOR TIANJIN WATER PROJECTS}

The bidding DSS of Tianjin water projects was designed and developed on the basis of above tender evaluation decision model. The framework and functions of it will be illustrated and described as below.

\section{A. The Framework of Bidding DSS}

The framework of the bidding DSS is a typical 3-layers system based on B/S (Browser/Sever), which is shown as Figure 1:

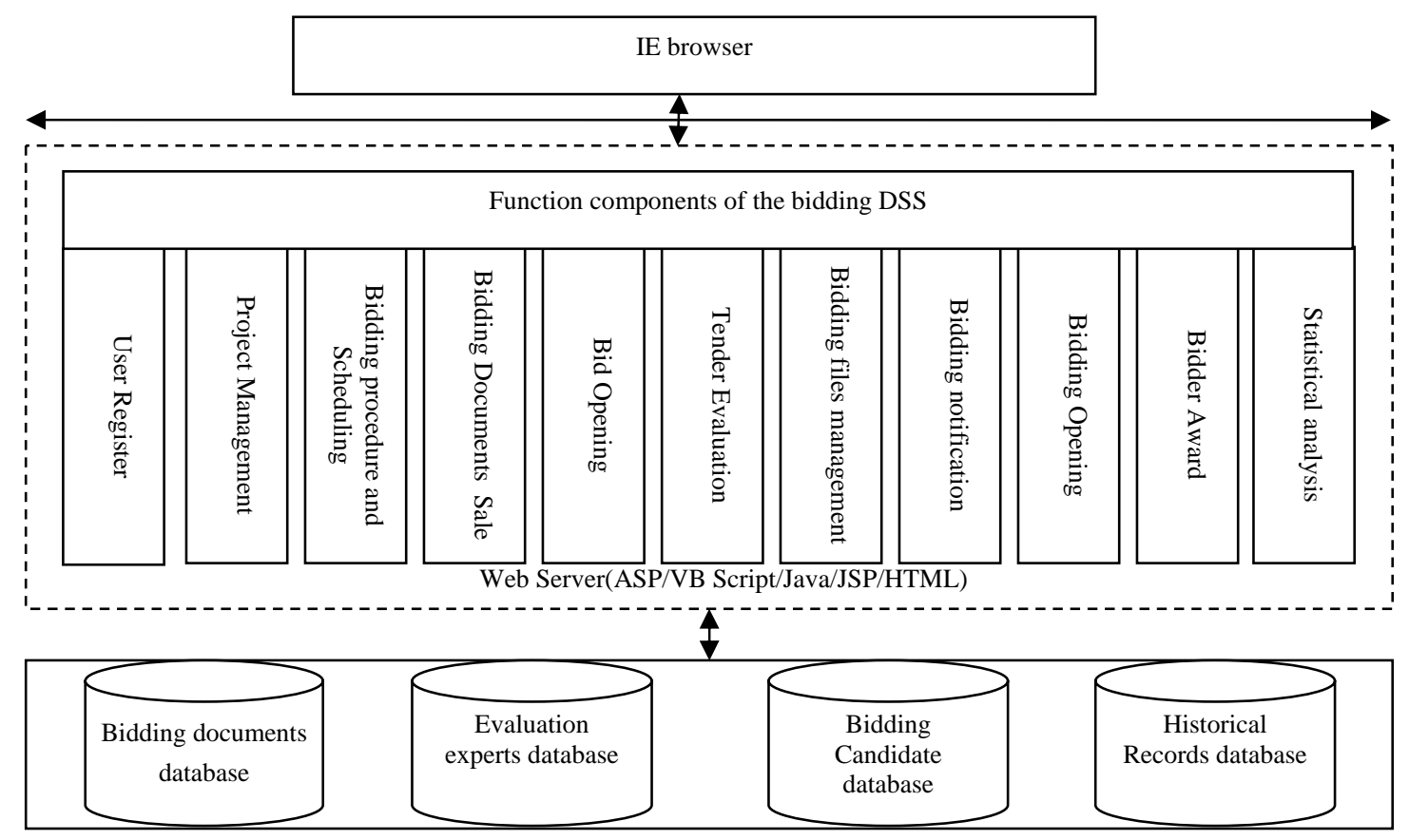

Figure 1. The system framework 
The first layer is the client tier, with which the users can completed workflow management of bidding process through IE browser. Bidders can query and browse the bidding information online through IE browser, then submit the tender in accordance with the requirements of the bidding through upload page. According to the prequalification conditions, the system will delete the bidders who can not satisfy it automatically, while qualified bidders will pass to the expert review system. After all experts scoring, each bidder's score will be evaluated by the tender evaluation model set up above. Finally, according to the total score rank, the candidate will be recommended to the employer, and the bidders can check the results through IE browser.

The second layer is the Web server tire which is used for function components and applications. In general, this layer includes the functional modules: user register, project management, bidding procedure and schedule, bidding documents sale, bidding opening, tender evaluation, bidding notification and award, statistical analysis, etc. The purpose of this layer is to realize bidding and award.

The third layer is the database server tire which is used for storing various project historical data, bidders' historical data, bidding files, etc. The purpose of it is to meet different requirements of various data sharing, querying and analyzing.

\section{B. Function Analysis and its Application}

The bidding DSS of water projects covers the whole process of bidding from project call for bid to commencement, concerning employers, bidders, evaluation experts, consultants and supervisory authorities. The system was divided into three subsystems: Project Management Subsystem, Bidding Process Management Subsystem and File Management Subsystem.

\section{1) Project Management Subsystem}

The mainly functions of project management subsystem are user registration, project call for bid, project bidding record management, project contract management and project commencement reports management, including some basic information about projects, bidding batches setting, bidding sections, which is shown in Figure 2;

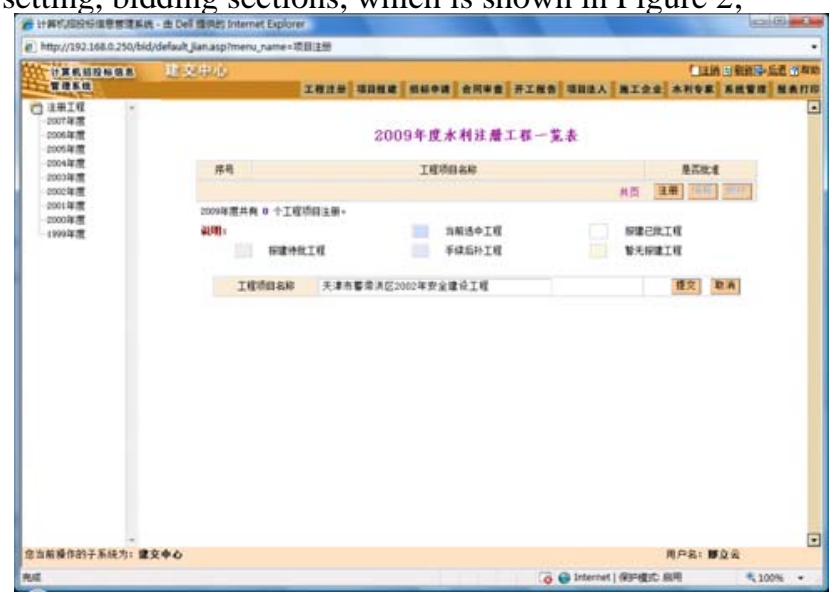

Figure 2. The interface of project management subsystem
Description of each function module:

- User Registration: user general information input, edit, inquiry, summary, etc.

- Project Call for Bid: the construction projects input, inquiry, statistics, print, output statement to Excel.

- Project Bidding Record Management: Project bidding partial information management, bidding application input, batches and segment inquiry, statistics, print, output statement to Excel.

- Project Contract Management: The contract review information input, inquiry, summary, print, output statement to EXCEL.

- Project Commencement Report Management: Project commencement report information input, inquiry, summary, print, output statement to EXCEL.

\section{2) Bidding Process Management Subsystem}

The bidding process management subsystem is the core of the bidding DSS, and other subsystems are auxiliary of it. Covering the whole procedures of bidding, this subsystem can reduce the experts' work, improve the efficiencies of it, and ensure the tender evaluation fair and objective. According to the bidding procedure, the functions of bidding process management system can be divided into following modules: bidding procedure and schedule, bidding documents sale, bid opening, tender evaluation, candidate recommendation, etc., as are shown in Figure 3:

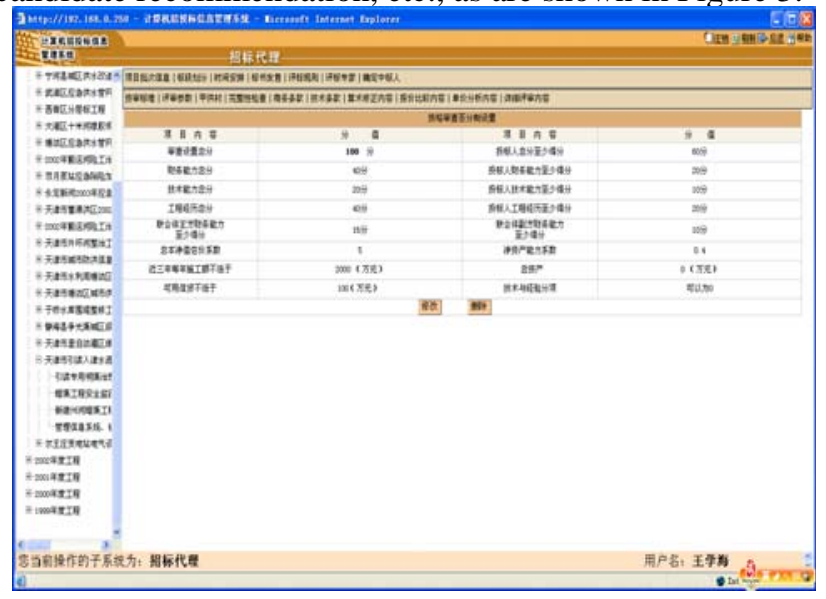

Figure 3. the interface of bidding process management subsystem

Function modules were described as followings.

- Bidding Procedure and Schedule: The function of it provides project register, modify, inquiry, and statistical analysis for project bidding, as well as time warning function, which can prevent the unreasonable or illegal time schedule automatically.

- Bidding Documents Sale Management: The function of it includes: user register, modify, inquiry, and statistical analysis etc.

- Bid Opening: According to the register sequence, the subsystem record the offer price of each bidder, and the unqualified bidders will be eliminated automatically.

- Tender Evaluation: This module is the core of the subsystems, which is based on the tender evaluation model 
built above and includes two sub-functions: tender evaluation management and expert management.

- Candidate Recommendation Management: Candidates will be ranked according the tender evaluation model, then, the suitable candidates will be recommended with appropriate forms.

3) File Management Subsystem

All files in the process of bidding will be managed by the file management subsystem, including information release, bidding documents management, tender invitations. The file management subsystem provides new file, edit, inquiry, and automatic analysis, etc, as are shown in Figure 4:

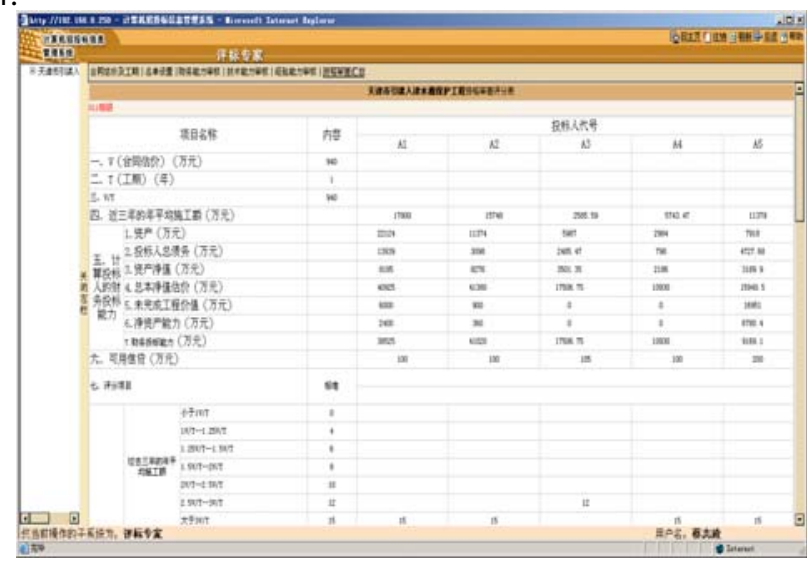

Figure 4. Interface of statistical analysis

\section{CONCLUSION}

In this paper, after a lot of literatures were reviewed and the bidding systems were referred and compared, the tender evaluation model was established and described, and the framework and functions of the new bidding DSS of water projects in Tainjin were designed and illustrated in detail. The applicability and practicability of the system had been demonstrated by a great number of water project biddings in Tianjin, which made the bidding work efficiency improved significantly and information shared rapidly and safely.

\section{REFERENCES}

[1] El-Mashaleh M S. Decision to bid or not to bid: a data envelopment analysis approach[J]. Canadian Journal Of Civil Engineering.2000,37(1),37-44.

[2] Gokhan Arslan, Mustafa Tuncan, M.Talat Birgonul, Irem Dikmen. Study and Realization of Internet-assisted Bidding System for Project[J]. 21st Control And Decision Conference,2005,(6),44404445.

[3] Park W.R. E-bidding proposal preparation system for projects[J].Journal of Construction Engineering and Management,2007,(5),112-115.

[4] KinOnn Wong. An Agent based Method for Generator Short Term Bidding in A Competitive Electricity Market[J]. Proceedings 8th International Conference on Advances in Power System Control, Operation and Management .2009,(07).

[5] Lu Yaobin, Zhu Zhiwei, Zhang Jinzhong, The Design and Implementation of Bidding \& Tendering System Based on Web[J], Computer Engineering and Applications, 2001, (23) :41-43.
[6] Wang Shenya, Design and Implementation of Internet Bidding System[D], Southwest Jiaotong University, 2004.

[7] HE Xiaoqin; Song Wei; Liu Weining, Study on Online Biddingapprise Model and Realization of System[J], Application research of computers, 2006,(05):77-79.

[8] Lv Zhiguo, Web-based Bidding for Construction Project Management, Information of China Constructio[J], 2009,(04):115118.

[9] Chen Dayuan, The Construction Project under Web Environment Long-range Public Bidding Enter a Bid Systematia Research[D], Wuhan University of Technology, 2003.

[10] Shi Hairong, Universal Network Bid and Tender System[D], Tianjin University, 2007.

[11] Deng Ronghui, Wang Yaowu, Evaluation of competitive performance of construction companies based on artificial neural network[J], Journal of Harbin Institute of Technology, 2006.(3):489484.

[12] Tian Zhong, Liu Yuming, Problems and Solution In Bidding Process for Landlord[J], Inner Mongolia Science Technology and Economy, 2004(15):130-132. 